\title{
Hydroxyapatite Coating on Silicon Nitride Surfaces Using the Biomimetic Method
}

\author{
Cecilia Chaves Guedes e Silva ${ }^{\mathrm{a} *}$, Eliana Cristina da Silva Rigo ${ }^{\mathrm{b}}$,Juliana Marchic, \\ Ana Helena de Almeida Bressianic, José Carlos Bressiani \\ ${ }^{a}$ Centro Tecnológico da Marinha em São Paulo - CTMSP, \\ Av. Prof Lineu Prestes, 2468, 05508-000 São Paulo - SP, Brazil \\ ${ }^{\mathrm{b}}$ Universidade São Francisco - USF, \\ R. Alexandre R. Barbosa, 45, 13251-900 Itatiba - SP, Brazil \\ 'Instituto de Pesquisas Energéticas e Nucleares, IPEN/CNEN, \\ Av. Prof. Lineu Prestes, 2242,05508-000 São Paulo - SP, Brazil
}

Received: March 30, 2007; Revised: March 11, 2008

\begin{abstract}
Silicon nitride based ceramics are promising candidates for biomedical applications due to their chemical and dimensional stability associated to suitable mechanical strength and relatively high fracture toughness. However, the bioinert characteristics of these ceramics limit their application to situations where the formation of chemical bonds between the material and the tissue are not essential. A way to broaden the application field of these ceramics in medicine is promoting their bioactivity by means of a hydroxyapatite coating. Therefore, in this paper, samples of silicon nitride were coated with apatite using the biomimetic method. The treated silicon nitride surface was characterized by diffuse reflectance infrared Fourier transformed, X ray diffraction and scanning electron microscopy. The results showed that a layer of hydroxyapatite could be deposited by this method on silicon nitride samples surface.
\end{abstract}

Keywords: bioceramic, silicon nitride, biomimetic method, hydroxyapatite

\section{Introduction}

Alumina and zirconia have been widely used as bioinert materials for clinical applications for several years, mainly owing their excellent biocompatibility. However, frequent fractures in implants produced by these ceramics have been resulted from the low fracture toughness of alumina and high degradation of zirconia in biological medium ${ }^{1,2}$.

Many ceramic materials have been researched to overcome the limitations of alumina and zirconia. Silicon nitride is a promising candidate due to its non-cytotoxicity ${ }^{5}$, high wear resistance, high thermal shock resistance and relatively high mechanical strength and fracture toughness ${ }^{3,4}$.

Once the bioinert ceramics do not form chemical bonds with the living tissues, their disadvantage is the bad fixation in the old bone ${ }^{1}$. An alternative would be to associate the excellent mechanical properties of the bioinert ceramics to the great superficial characteristics of those bioactive.

The biomaterials classified as bioactive have the important ability to form chemical bonds with the living host tissues, decreasing the possibility of rejection processes and fixation problems of the prostheses ${ }^{1}$. However, the bioactive materials present low mechanical strength, limiting their use in situations where mechanical stress is present ${ }^{1}$.

Different methods have been studied and proposed to produce biomaterials with high mechanical properties and bioactivity, such as the production of glass-ceramic ${ }^{5}$, biocomposite $^{6}$ and substrate coatings with a bioactive layer of calcium phosphate ${ }^{7-12}$. It is related that this properties combination can really enhance the clinical success of a metal implant ${ }^{13}$.

Among the available methods of substrates coating with calcium phosphate, the plasma spraying is the most common, although it cannot provide coatings on porous surfaces ${ }^{5}$ and the applied coatings have a poor quality because of the difficult to control their composition, crystal phase and cristallinity ${ }^{8,9}$.

Other coating techniques which have been investigated include electrodeposition ${ }^{10}$, sputter deposition ${ }^{11}$ and sol-gel ${ }^{12}$. An ideal method to produce hydroxyapatite $\mathrm{Ca}_{10}\left(\mathrm{PO}_{4}\right)(\mathrm{OH})_{2}(\mathrm{HA})$ coatings on materials for biomedical applications is the biomimetic coating ${ }^{14-16}$. By this method, a bone-like apatite surface layer can be produced in an acellular simulated body fluid (SBF) with ions composition similar to that of inorganic part of human blood plasma ${ }^{17}$. Two steps are involved in the process: i) nucleation and ii) precipitation and growth of the apatite layer. The first step occurs during the immersion of the ceramic surface into a synthetic solution simulating the blood plasma, i.e., into the simulated body fluid (SBF), containing a nucleant agent. The second step is consequence of a subsequent immersion of the ceramic surface into a concentrated simulated body fluid $(1.5 \mathrm{SBF})^{15}$.

The nucleant in the conventional biomimetic method agent is a bioglass, but there is another biomimetic method in which the nucleant agent is a sodium silicate solution ${ }^{11}$. By using a sodium silicate solution, the second step of the method (precipitation and growth) is promoted by the immersion of the ceramic surface into the 1.5 SBF. This procedure is adopted so that the reactions could happen as follows: i) adsorption of silicates ions of the solution on the ceramic surface; ii) nucleation of hydroxyapatite on the adsorbed ions and iii) growth of the hydroxyapatite nuclei and growth of the thickness of the layer ${ }^{14}$. Previous works performed with different substrates showed the used concentration of sodium silicate is adequate to promote a hydroxyapatite layer at the end of the coating process ${ }^{14,16}$. 
Hence, the aim of this work is to obtain a silicon nitride with bioactive surface characteristic, using the biomimetic method with a sodium silicate solution as nucleant agent.

\section{Materials and Methods}

\subsection{Sample preparation and characterization}

As starting materials, powders of $\mathrm{Si}_{3} \mathrm{~N}_{4}$ (M11, Hermann C. Starck; with $92.7 \% \alpha-\mathrm{Si}_{3} \mathrm{~N}_{4}$ and $1.14 \%$ wt oxygen), $\mathrm{Y}_{2} \mathrm{O}_{3}$ (Hermann C. Starck; purity $>99.9 \%) ; \mathrm{Yb}_{2} \mathrm{O}_{3}$ (Sigma Aldrich Chemical; purity > 99.9\%) and $\alpha-\mathrm{Al}_{2} \mathrm{O}_{3}$ (16 SG Alcoa, purity $>99.9 \%$ ) were used. Powders corresponding to the composition $91 \mathrm{Si}_{3} \mathrm{~N}_{4}-3 \mathrm{Y}_{2} \mathrm{O}_{3}-3 \mathrm{Yb}_{2} \mathrm{O}_{3}-3 \mathrm{Al}_{2} \mathrm{O}_{3}$ (in wt. (\%)) were ground in an atrittor mill with isopropanol as the liquid vehicle. The ground and homogenized powder mixture was dried at $90{ }^{\circ} \mathrm{C}$, pressed uniaxially at $50 \mathrm{MPa}$ followed by cold isostatic pressing at $200 \mathrm{MPa}$.

The samples were fired at $1750{ }^{\circ} \mathrm{C}$ for 60 minutes in a carbon resistance furnace using a nitrogen atmosphere and then analysed by $\mathrm{X}$ ray powder diffraction (Siemens D5000) to verify the crystalline phases. In order to observe the shape and grain size and their distribution by scanning electron microscopy (Jeol, JXA 6400), the surface samples were polished and plasma etched using $\mathrm{CF}_{4}$ and $\mathrm{O}_{2}$.

\subsection{Coating by the biomimetic method}

\subsubsection{Preparation of the solutions}

The solutions employed to promote the biomimetic coating were a sodium silicate solution (SS) and a $1.5 \mathrm{SBF}$ (Table 1). The preparation of the solutions involved the dissolution of the reagents $\mathrm{NaCl}$, $\mathrm{KCl}, \mathrm{K}_{2} \mathrm{HPO}_{4}, \mathrm{CaCl}_{2} .2 \mathrm{H}_{2} \mathrm{O}, \mathrm{MgCl}_{2} \cdot 6 \mathrm{H}_{2} \mathrm{O}, \mathrm{NaHCO}_{3}, \mathrm{Na}_{2} \mathrm{SO}_{4}$ and $\left(\mathrm{Na}_{2} \mathrm{O}\right) \cdot \mathrm{SiO}_{2}$ into distilled and deionized water. The $\mathrm{pH}$ of the solutions was controlled with $\mathrm{HCl}\left(0.1 \mathrm{~mol} . \mathrm{dm}^{-3}\right)$ and tris-hydroxymethyl aminomethane $\left(0.05 \mathrm{~mol} . \mathrm{dm}^{-3}\right)$ to get a value of 7.25 at $37^{\circ} \mathrm{C}$. After the preparation, the $\mathrm{SS}$ and $1.5 \mathrm{SBF}$ solutions were kept in polypropylene flasks.

\subsubsection{Coating of the silicon nitride surfaces}

Rectified samples of silicon nitride were exposed to sodium silicate solution (SS) at $37{ }^{\circ} \mathrm{C}$ for seven days. After the incubation period, the samples were washed in distilled and deionized water and dried at room temperature, so that they could be immersed into $1.5 \mathrm{SBF}$.

The samples were soaked in $1.5 \mathrm{SBF}$ for six days at $37^{\circ} \mathrm{C}$ and the solution was changed every two days. At the end of this period, the procedure of washing and drying of the samples was carried out.

The coating was characterized by diffuse reflectance infrared Fourier transformed (DRIFT) (Perkin Elmer Spectrum GX FT-IR System), X ray diffraction (Siemens D5000) and scanning electron microscopy (Philips, XL30-FEG) with energy dispersion spectroscopy (EDS).

\section{Results and Discussion}

The microstructure of the silicon nitride surface, without the coating, is shown in Figure 1. It is possible to notice the elongated shape of the $\beta-\mathrm{Si}_{3} \mathrm{~N}_{4}$ grains which increases the mechanical properties of such materials ${ }^{18}$. Elongated grains as those of $\beta-\mathrm{Si}_{3} \mathrm{~N}_{4}$ induce to different toughness mechanisms, inhibiting the propagation of cracks that can be created by an initial failure ${ }^{19}$. More elongated grains, i.e., grains with high aspect ratio, increase the crack deflection amplitude, resulting in high values of fracture toughness ${ }^{18}$, as those obtained by us in earlier studies ${ }^{3}$.

Based on the infrared spectra of the silicon nitride sample surface without coating (Figure 2), we can observe the presence of bands in the regions of $454,590,1025,1202 \mathrm{~cm}^{-1}$ related to the possible vibrations of the bonds $\mathrm{Si}-\mathrm{O}$ and $\mathrm{Si}-\mathrm{N}$ in $\mathrm{Si}_{3} \mathrm{~N}_{4}{ }^{20,21}$. Besides, there is a band in the region of about $2300 \mathrm{~cm}^{-1}$ owing to the equipment background.

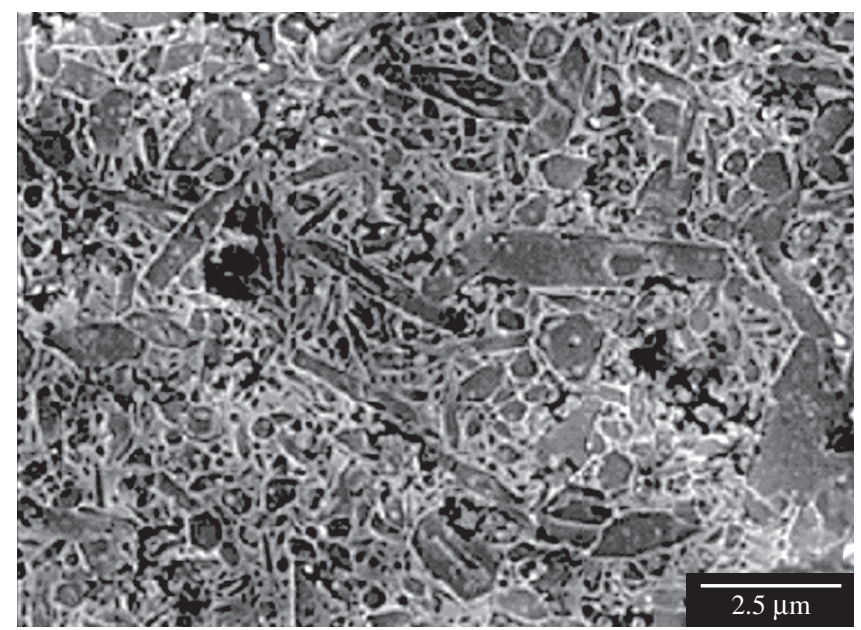

Figure 1. Scanning electron micrograph (SEM) of polished and etched sample surface of silicon nitride.

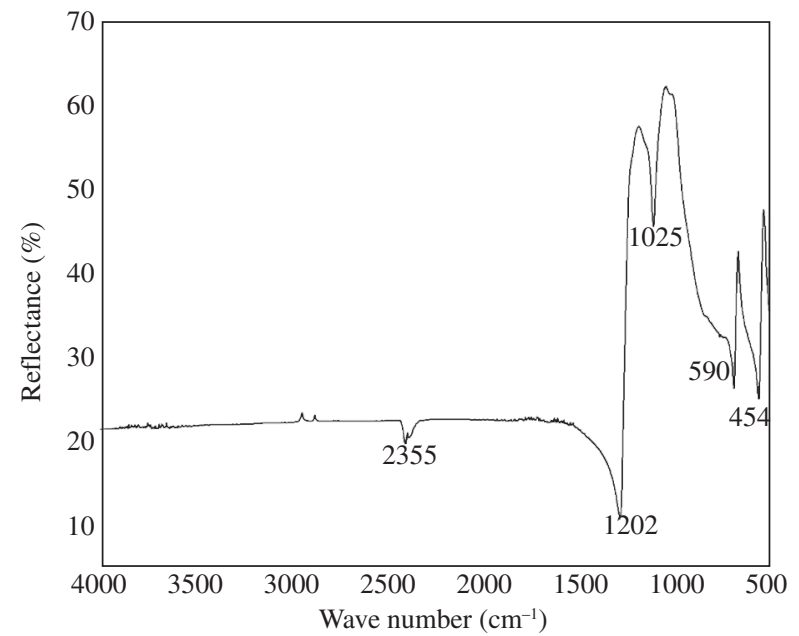

Figure 2. Diffuse reflectance infrared Fourier transformed (DRIFT) spectra of a silicon nitride sample without hydroxyapatite coating.

Table 1. Ionic content of the used solutions $\left(\mathrm{mmol} \cdot \mathrm{dm}^{-3}\right)$.

\begin{tabular}{lrcccccccc}
\hline & $\mathrm{Na}^{+}$ & $\mathrm{K}^{+}$ & $\mathrm{Ca}^{2+}$ & $\mathrm{Mg}^{2+}$ & $\mathrm{SiO}_{3}^{2-}$ & $\mathrm{HCO}_{3}^{-}$ & $\mathrm{Cl}^{-}$ & $\mathrm{HPO}_{4}^{2-}$ & $\mathrm{SO}_{4}^{2-}$ \\
\hline $1.5 \mathrm{SBF}$ & 213.0 & 7.5 & 3.8 & 2.3 & - & 6.3 & 223.0 & 1.5 & 0.75 \\
$\mathrm{SS}$ & 2.0 & - & - & - & 3.6 & - & 1.0 & - & - \\
\hline
\end{tabular}




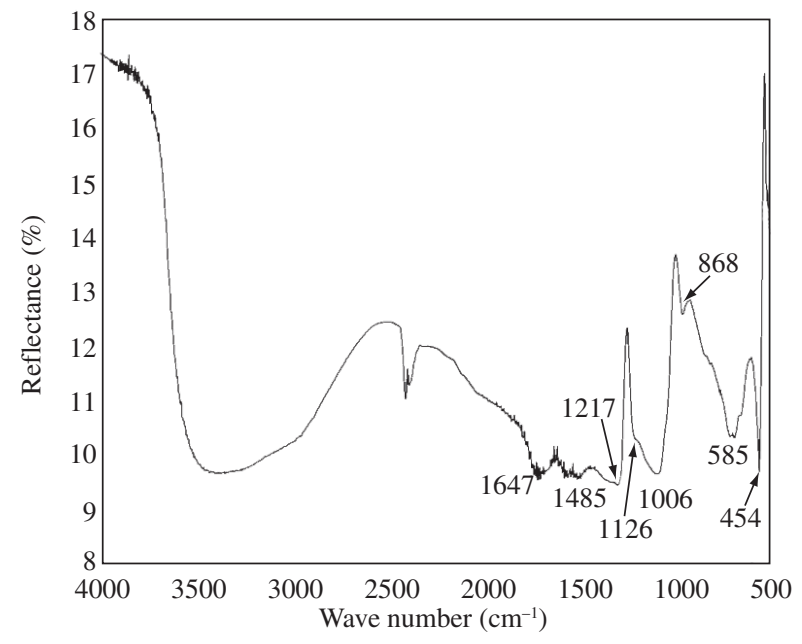

Figure 3. Diffuse reflectance infrared Fourier transformed (DRIFT) spectra of a silicon nitride sample with hydroxyapatite coating.

After the immersion of the substrate into the sodium silicate solution (SS) with subsequent immersion into 1.5 SBF, broad and defined bands in the regions of 585, 1010 and $1100 \mathrm{~cm}^{-1}$ were identified on the silicon nitride surface (Figure 3) which are typical of the $\mathrm{PO}_{4}^{3-}$ vibrations. Besides, weak bands in the regions of 868 and $1485 \mathrm{~cm}^{-1}$ can be verified and are associated with the $\mathrm{CO}_{3}{ }^{2-}$ vibrations. Typical bands of $\mathrm{H}_{2} \mathrm{O}$ and $\mathrm{OH}^{-}$can also be noted in the regions of $1647 \mathrm{~cm}^{-1}$ and between 3000 and $3600 \mathrm{~cm}^{-1}$, respectively with are in good agreement with other studies ${ }^{22-26}$

The related results indicate the apatite formation on silicon nitride surfaces after treatment with the biomimetic method. The apatite nucleation on silicon nitride surface can be attributed to two factors. The first of them is associated with $\mathrm{Si}-\mathrm{OH}$ bonds, formed by the adsorption of the SS solution ions, on the silicon nitride surface. The second factor is the hydration of the present silica layer on the surface of silicon nitride. After the formation of apatite nuclei, they could grow by the immersion into $1.5 \mathrm{SBF}$.

Also, the apatite coating on silicon nitride substrate by using a silicate sodium solution as nucleant agent demonstrates that the presence of $\mathrm{P}_{2} \mathrm{O}_{5}$ is not really essential as researchers thought to be in earlier studies ${ }^{15}$. This results is in good agreement with Kokubo ${ }^{15}$ that showed an apatite layer on $\mathrm{P}_{2} \mathrm{O}_{5}$-free glasses, as those of the system $\mathrm{Na}_{2} \mathrm{O}-\mathrm{CaO}-\mathrm{SiO}_{2}$, can be formed by the contact with SBF. According to Kokubo ${ }^{15} \mathrm{Na}^{+}$and $\mathrm{Ca}^{2+}$ ions of glasses as $\mathrm{Na}_{2} \mathrm{O}-\mathrm{SiO}_{2}$ or $\mathrm{CaO}-\mathrm{SiO}_{2}$ tend to be changed by $\mathrm{H}_{3} \mathrm{O}^{+}$ions that are within the solution, forming $\mathrm{Si}-\mathrm{OH}$ groups on their surfaces. These $\mathrm{Si}-\mathrm{OH}$ groups induce the apatite nucleation ${ }^{15,28}$. After the formation of apatite nuclei, its growth is spontaneous as consequence of subsequent depositions of calcium and phosphates ions that are present in the solution.

The morphology of the apatite layer formed on silicon nitride surfaces after the immersion into $1.5 \mathrm{SBF}$ was analyzed by scanning electron microscopy and energy dispersion spectroscopy (EDS). Calcium, phosphorous, magnesium, sodium, chlorine, silicon, oxygen and carbon ions were identified (Figure 4), confirming the presence of $\mathrm{PO}_{4}{ }^{3-}$ and $\mathrm{CO}_{3}{ }^{2-}$ groups identified by DRIFT (Figure 3 ) and leading the formation of hydroxycarbonate apatite $(\mathrm{HCA})^{17}$.

The $\mathrm{X}$ ray diffraction patterns of both uncovered and covered substrates are shown in Figure 5. By Figure 5a, only $\beta-\mathrm{Si}_{3} \mathrm{~N}_{4}$ was identified as crystalline phase. It was also observed that the peaks

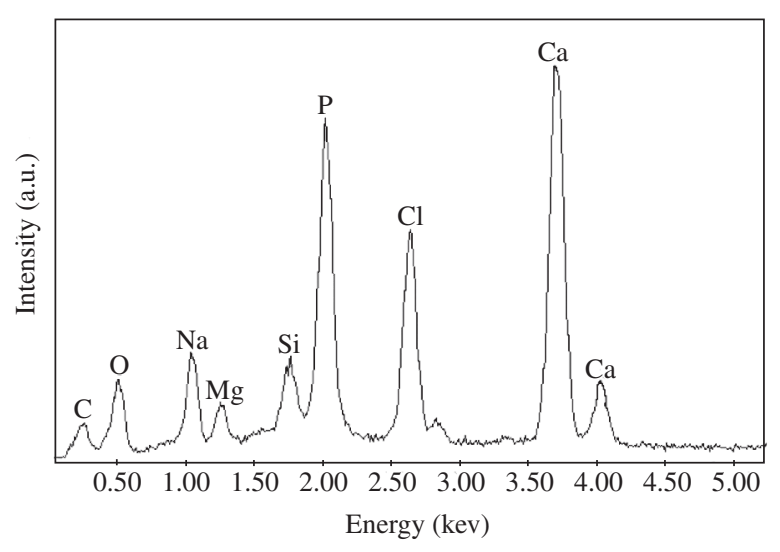

Figure 4. Chemical analysis obtained by energy dispersion spectroscopy (EDS) of the layer formed on the silicon nitride surface.

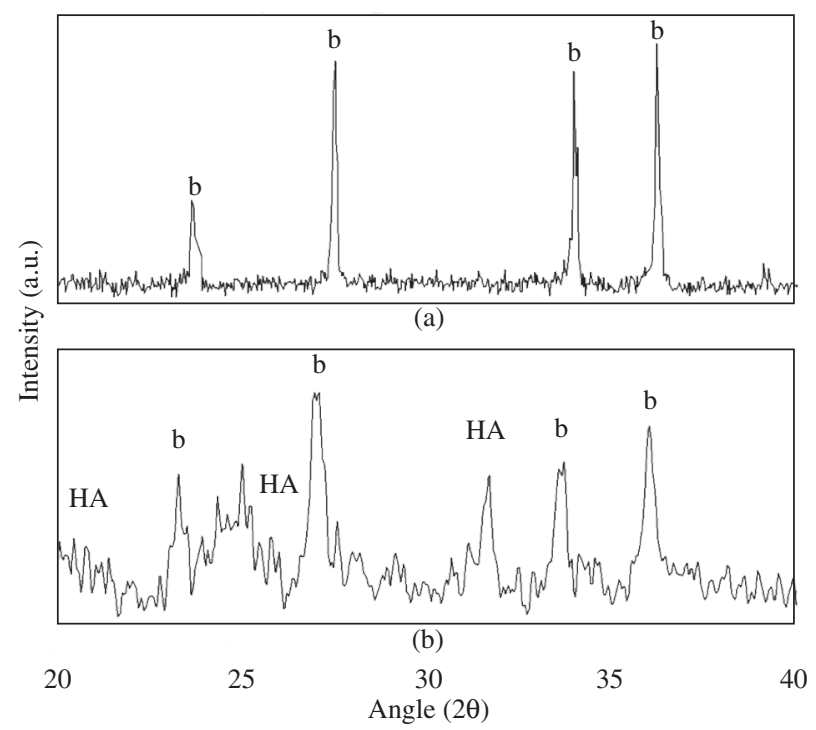

Figure 5. X ray diffraction (XRD) spectra taken from a) silicon nitride substrate and b) silicon nitride sample covered by a hydroxyapatite layer (HA), using SS as nucleant agent (b is $\beta-\mathrm{Si}_{3} \mathrm{~N}_{4}$ ).

of coated silicon nitride (Figure 5b) had their intensity decreased as compared with uncoated one (Figure 5a). Besides, the presence of broad peaks of hydroxyapatite were identified, confirming that the layer obtained on the silicon nitride surfaces, after the treatment with the biomimetic method, is predominantly formed by HCA. These results are in good agreement with those obtained by diffuse reflectance infrared Fourier transformed and energy dispersion spectroscopy.

The micrograph illustrated in the Figure 6 shows the coating is characterized by a dense layer with dispersed globules. The cracks in the covering are associated with the drying process, conducted at room temperature, in air. The morphology of the layer formed on silicon nitride surfaces is very similar to that of the coatings obtained on titanium and titanium-alloys surfaces when the biomimetic method is used ${ }^{19,22}$. These results indicated the affinity of the precipitates with silicon nitride based ceramic, suggesting that this material has adequate superficial features to become bioactive. 


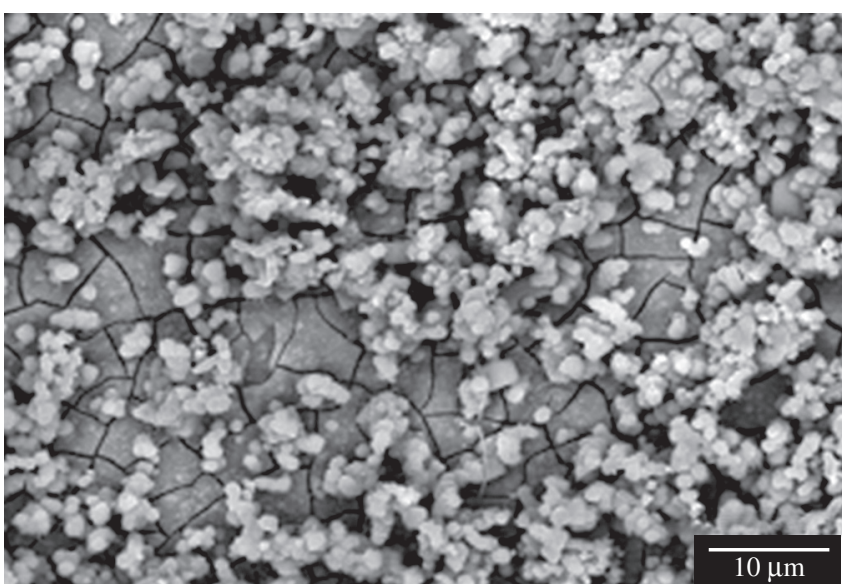

Figure 6. Scanning electron micrograph (SEM) of the silicon nitride surface coated by a hydroxyapatite layer, using SS as nucleant agent.

\section{Conclusions}

The obtained results showed that the biomimetic method promoted the deposition of a dense layer of hydroxyapatite on silicon nitride surfaces. Also, the propitious microstructure and the relatively high value of fracture toughness observed for the silicon nitride substrate in earlier studies, associated to the bioactive surface promoted by the biomimetic coating, may lead to the development of a biomaterial with excellent interaction with the living tissues, as well as great mechanical properties.

\section{References}

1. Hench LL. Bioceramics: from concept to clinic. J. Am. Ceram. Soc. 1984; 74(7): 1487-1510.

2. Maccauro G, Piconi C, Burger W, Pilloni L, de Santis E, Muratori F, Learmonth ID. Fracture of a Y-TZP ceramic femoral head. Analysis of a fault. J. Bone Joint Surg. 2004; 86b(8): 1192-1196.

3. Guedes e Silva CC, Higa OZ, Bressiani JC. Cytotoxic evaluation of silicon nitride based ceramics. Mater. Sci. Eng. C. 2004; 24(5): 643-646.

4. Kue R, Sohrabi A, Nagle D, Frondoza C, Hungerford D. Enhanced proliferation and osteocalcin production by human osteoblast-Like MG63 cells on silicon nitride ceramic discs. Biomaterials. 1999; 20(13): 1195-1201.

5. Kokubo T. Apatite formation on surfaces of ceramics, metals and polymers in body environment. Biomaterials. 1991; 12(2): 155-163.

6. Amaral M, Costa MA, Lopes MA, Silva RF, Santos JD, Fernandes, MH. $\mathrm{Si}_{3} \mathrm{~N}_{4}$-bioglass composites stimulate the proliferation of MG63 osteoblast-like cells and support the osteogenic differentiation of human bone marrow cells. Biomaterials. 2002; 23(24): 4897-4906.

7. Habibovic $\mathrm{P}$, Barrère $\mathrm{F}$, van Blitterswijk CA, Groot $\mathrm{K}$, Layrolle P. Biomimetic Hydroxyapatite Coating on Metal Implants. J. Am. Ceram. Soc. 2002; 85(3): 517-522.

8. Ha SW, Reber R, Ecjert KL, Petitmermet M, Mayer J, Wintermanterl E, Baerlacher $\mathrm{CH}$, Gruner H. Chemical and morphological changes of vacuumplasma-sprayed hydroxyapatite coatings during immersion in simulated physiological solutions. J. Am. Ceram. Soc. 1998; 81(1): 81-88.

9. Ducheyne P, van Raemdonck W, Heughbaert JC, Heughbaert M. Structural analysis of hydroxyapatite coatings on titanium. Biomaterials. 1986; 7(2): 97-103.
10. Park JH, Lee DY, Oh KT, Lee YK, Kim KM, Kim KN. Bioactivity of calcium phosphate coatings prepared by electrodeposition in a modified simulated body fluid. Materials Letters. 2006; 60(21-22): 2573-2577.

11. Ektessabi AM. Surface modification of biomedical implants using ionbeam-assisted sputter deposition. Nuclear Instruments and Methods in Physics Research B. 1997; 127/128:1008-1014.

12. Gan L, Pilliar R. Calcium phosphate sol-gel-derived thin films on porous-surfaced implants for enhanced osteoconductivity. Part I: Synthesis and characterization. Biomaterials. 2004; 25(22): 5303-5312.

13. Havelin LI, Engesaeter LB, Espehaug B, Furnes O, Lie SA, Vollset SE. The Norwegian arthroplasty register: 11 years and 73,000 arthroplasties. Acta Orthop. Scand. 2000; 71(4): 337-353.

14. Rigo ECS, Boschi AO, Yoshimoto M, Allegrini Jr. S, Konig Jr. B, Carbonari MJ. Evaluation in vitro and in vivo of biomimetic hydroxyapatite coated on titanium dental implants. Mater. Sci. Eng. C. 2004; 24(5): 647-651.

15. Kokubo T. Apatite formation on surfaces of ceramics, metals and polymers in body environment. Acta Mater. 1998; 46(7): 2519-2527.

16. Rigo ECS, Santos LA, Carrodeguas RG, Boschi AO. Bonelike apatite coating on Ti6Al4V: novel nucleation process using sodium silicate solution Mater. Sci. Forum. 2003; 416-418: 658-662.

17. Jonasova L, Muller FA, Helebrant A, Strnad J, Greil P. Hydroxyapatite formation on alkali-treated titanium with different content of $\mathrm{Na}+$ in the surface layer. Biomaterials. 2002; 23(15): 3095-3101.

18. Faber KT, Evans AG. Crack deflection process - I. Theory. Acta Metall. 1983; 31(4): 565-576.

19. Onji T, Hinao K, Kanzaki S. Fracture resistance behavior of highly anisotropic silicon nitride. J. Am. Ceram. Soc. 1995; 78(11): 3125-3128

20. Yokoyama S, Goto H, Miyamoto T, Ikeda N, Shibahara K. Atomic layer controlled deposition of silicon nitride and in situ growth observation by infrared reflection absorption spectroscopy. Applied Surface Science. 1997; 112:75-81.

21. Rudolphi M, Bruns M, Baumann H, Geckle U. High purity Si-C-N thin films with tailored composition on the tie line $\mathrm{SiC}-\mathrm{Si}_{3} \mathrm{~N}_{4}$. Diamond and Related Materials. 2007; 16(4-7): 1273-1277.

22. Barrere F, van Blitterswijk C, de Groot K, Layorolle, P. Nucleation of biomimetic Ca-P coatings on Ti6Al4V from a SBF x 5 solution: influence of magnesium. Biomaterials. 2001; 23(10): 2211-2220.

23. Stoch A, Jastrzebski W, Brozek A, Trybalska B, Cichocinska M, Szarawara E. FTIR monitoring of the growth of the carbonate containing apatite layers from simulated and natural body fluids. J. Molecular Structure. 1999; 511-512(23): 287-294.

24. Klee WE, Engel GIR. spectra of the phosphate ions in various apatites. Inorg. Nucl. Chem. 1970; 32: 1837-1843.

25. Slósarczyk A, Paluszkiewicz C, Gawlicki M, Paszkiewicz Z. The FTIR spectroscopy and QXRD studies of calcium phosphate based materials produced from the powder precursors with different $\mathrm{Ca} / \mathrm{P}$ ratios. Ceram. Int. 1997; 23(4): 297-304.

26. Stoch A, Jastrzebski W, Brozek A, Stoch J, Szaranice J, Trybalska B, Kmita G. FTIR absorption-reflection study of biomimetic growth of phosphates on titanium implants. J. Molecular Structure. 2000; 555(1-3): 375-382.

27. Vallet-Regí M. Biocerámicas. Anales de la Real Sociedad Española de Química. 2003; 99: 167-175.

28. Kokubo T. Formation of biologically active bone-like apatite on metals and polymers by a biomimetic process. Thermo. Acta. 1996; 280-281: 479-490. 